O autor responde

Theauthor replies

Quais as nossas divergências sobre a política social no Brasil? Uma réplica

What are our disagreements on social policy in Brazil? A retort

Os comentários de M aria Lúcia Vianna, Eduardo Fagnani, Jeni Vaitsman eCarlos Pereira trazem elementos extremamenteesclarecedores ao debatesobre a formação do sistema de proteção social no Brasil contemporâneo. A complexidade e a argúcia das observaç̃os valorizam, em muito, os objetivos do meu texto, estimulando o debate sobre alguns dos problemas teóricos e metodológicos das ciências sociais contemporâneas. Agradeço a leitura cuidadosa dos autores do meu texto, que discute fundamentalmente a natureza do desenvolvimento social brasileiro recente. Ao concordar em submeter meu texto à leitura crítica, não esperava consenso. Sabia que teria um trabal ho adicional na tentativa de manter os meus argumentos e evidências após as esperadas críticas agudas dos debatedores. Quero destacar que, ao responder algumas das questões assinaladas pelos comentaristas, viso essencialmente precisar os meus argumentos e não retificar de maneira unilateral os comentários ao meu texto.

\section{Minha réplica}

Sobre o institucionalismo: M aria Lúcia Vianna questiona a validade da escolha dos argumentos das "regras instituídas" para explicar processos de políticas públicas. Esclareço que a opção metodológica usada no meu texto está ancorada em um dialogo implícito com os teóricos do institucionalismo comparativo e histórico ${ }^{1}$. Os autores desta linhagem têm tentado explicar a dinâmica de processos políticos de "nível médio" nas sociedades contemporâneas. Esta busca de alternativas às explicações estruturais e funcionais me parece de algum modo útil para explicar políticas setoriais e experiências organizacionais. Existem poucas opções rivais, tão ou mais satisfatórias, aplicadas a casos concretos.

As instâncias de nível médio podem ser os partidos políticos, os grupos de interesse econômicos, como sindicatos e associações. Identifico, no meu texto, o sistema de proteção social brasileiro, nas suas diversas configurações setoriais, como um conjunto de instituições que faz a mediação, ao nível da esfera política, entreo financiamento público e a provisão de bens públicos.

No meu entendimento, esta mediação permite configurar estesistema de proteção social como um objeto específico de pesquisa que, embora constrangido pela dinâmica da acumulação capitalista, apresenta um desenvolvimento de idéias e interesses próprios.

Esta precisão de escopo na análise ajuda a identificar dequemaneira uma instância de nível intermediário - o sistema de proteção social - constrange as tendências macroestruturais - por exemplo, os interesses estruturais de parcela da eliteinteressada no monopólio na destinação dos recursos públicos para as funções diretas de acumulação.

Esta foi uma opção consciente contra os argumentos excessivamente estruturalistas, especialmente defendidos por economistas preocupados com políticas sociais no Brasil, quetêm feito uma exagerada subordinação da área social brasileira à dinâmica da acumulação ou aos interesses econômicos imediatos da elite dominante. Este um dos pontos importantes da minha divergência com os comentários de Fagnani, que comento adiante.

Não existeevidência alguma que comproveque as classes dominantes brasileiras apresentem um padrão homogêneo de decisão sobre o gasto público orientado pela lógica exclusiva do mercado. Ao contrário, o processo decisório na esfera pública é fortemente mediado pelo cálculo da patronagem e pela busca de sobrevivência política. As estratégias de patronagem ede troca política favorecem a criação de instâncias públicas, de provisão de bens e serviços, subordinadas, na maioria dos casos, ao cálculo da sobrevivência das coalizões eleitorais ou ao sucesso da gestão do Executivo. 0 sistema de 
proteção social brasileiro apresenta, efetivamente, este traço estrutural de articulação com a patronagem. É ainda pouco compreendido o efeito del eté rio do arranjo de patronagem sobre a eficiência ea qualidade na provisão dos bens públicos. As elites nacionais atuariam, neste contexto, como força de obstrução às iniciativas de modernização das condições organizacionais de provisão de bens públicos. A perspectiva teórica que destaca o poder de veto das elites ébem atraente, no meu entendimento, para compreender a dinâmica organizacional do setor público. Por isso, mesmo que cresça constantemente a oferta física de serviços públicos, esta expansão não gera benefícios públicos.

Por esta razão, em nenhum momento deixo transparecer que a criação no Brasil do complexo sistema de proteção social resolve o problema da inclusão e da superação da dívida social brasileira. Permanecea questão dasfalhas estruturais dequalidadee eficiência da provisão pública, queéuma das ameaças fundamentais à sustentabilidade do país.

A vitória dePirro - mais inquietante que as restrições ao modelo institucionalista - é a pergunta de Vianna sobre a natureza da vitória do arranjo institucional da CF de 1988 sobre a dinâmica do ajuste. Diz Vianna: Não há como negar queo sistema brasileiro de proteção social resistiu às pressões pelo desmonte nos anos 90. Comparadas às reformas então levadas a cabo por muitos outros países da Amé rica Latina, as realizadas no Brasil foram suaves. A seguridade social continuou inscrita na Lei, a previdência social manteve se pública, a saúde preservou seu caráter universal, os benefícios constitucionais de assistência permaneceram. Nesse sentido, coube vitória à agenda institucionalista no embate com a agenda do ajuste macroeconômico. Teria sido, contudo, uma vitória de Pirro?

A autora responde quea implementação do sistema de proteção social no Brasil foi inconclusa porqueo arranjo da seguridade social unificada não foi levado adiante. Afirma a autora: sem uma coordenação geral, sem nenhuma instância de integração - o Conselho N acional de Seguridade foi extinto em 1999 - e sem um orçamento próprio, a seguridade [social] deixou de existir concretamente. Todavia, os recursos que a Constituição Ihe atribuiu continuaram a fluir para os cofres públicos.

Estes são argumentos realmente inqui etantes e importantes. Está em jogo, nesta afirmação da autora, avaliar a exata medida do que possa ser considerado um bom sistema de proteção social. Dois pontos devem ser considerados:

Primeiro, penso que a existência de uma coordenação unificada e orçamento próprio da seguridade social - integrando a gestão dos setores de saúde, educação e previdência social, por exemplo - não podeser o único indicador que definea virtude de um sistema de proteção social. M esmo as economias com sistemas de proteção com substanciais traços de virtude redistributiva não apresentam o padrão de unicidade na seguridade social sugerido por Vianna. Talvez seja necessário também avaliar o sistema de proteção social por meio de outras dimensões complementares, tais como 0 nível de inclusão social, a equidade no acesso aos ben efícios e presteza e qualidade dos serviços prestados independente da lógica do mercado. Cohen e Franco apresentam argumentos extremamente interessantes para a avaliação de políticas públicas sociais². Creio que a expressão final de uma vitória de Pirro do arranjo institucional da proteção social no Brasil pode estar mais associada às falhas de provisão - decorrentes do subfinanciamento ou da ineficiência do setor público - do que ao déficit de coordenação previsto pelo arranjo original da seguridade social. A baixa capacidade de prover qualidade pode explicar, em parte, a universalização excludente característica da provisão de assistência na saúde e na educação.

Segundo, a coordenação geral pela seguridade social não impediria os conflitos distributivos entre os diferentes setores por força das diferenças na forma de provisão de benefícios, clientelas, comunidades de especialistas, profissões e compromissos federativos. Poderia aumentar substancial mente os custos transacionais de implementação de inovações nestas políticas setoriais.

Continuidade: 0 argumento de Eduardo Fagnani contra a minha tese da continuidade entre os governos da FHC e Lula na proteção social busca atingir um alvo mais amplo: a negação do universal ismo no Brasil pela presença da focalização. Diz Fagnani: em primeiro lugar, não é adequado considerar a focalização como a continuidade da agenda da redemocratização. A agenda da redemocratização era baseada no paradigma do Estado de Bem-Estar Social ea focalização éa antítese desseparadigma. Ao invés da continuidade, a focalização foi uma cunha aberta pelas forças do mercado para inserir o Estado Mínimo na agenda.

Ao contrário do entendimento do autor, no meu texto, não associo a focalização à redemocratização. Defendi que a focalização éum resultado direto da agenda do ajuste macroeconômico e não da democratização. 0 maior paradoxo - objeto central da minha análise - é a sua permanência e ampliação no governo Lula, gerando o complexo arranjo de proteção existente no país. Não tenho divergência com o autor sobre os efeitos negativos do paradigma do ajuste sobre políticas setoriais locali- 
zadas. As políticas de saneamento e habitação são bons exemplos de estagnação; porém, não existem evidências que permitam afirmar, como conclui Fagnani, que o sistema de proteção social brasileiro foi mutilado, com sucesso, pelas autoridades econômicas brasileiras, nem que as políticas universalistas tenham sido obstaculizadas na sua totalidade. M esmo a hipótese de existência de uma política pública explícita eativa para desorganizar o mercado de trabalho deve ser considerada com extrema cautela. Não é sustentável, igualmente, que uma agenda liberal tenha alterado radicalmente os fundamentos da previdência social no Brasil.

Estratégia macroeconômica versus estratégia de desenvolvimento social - Fagnani argumenta que a estratégia macroeconômica adotada no Brasil é essencialmente antagônica ao desenvolvimento social. Em suas próprias palavras, 0 argumento central que defendo é que, no período 1990-2006, houve extrema incompatibilidade entre a estratégia macroeconômica e de reforma do Estado, central e hegemônica na agenda governamental, e as possibilidades efetivas de desenvolvimento e inclusão social.

Esta é uma argumentação extremamente complexa porque traz implícita a idéia de que houve uma descontinuidade na estratégia macroeconômica após 2006 no Brasil. N este caso, teria havido uma profunda mudança nas condições de gestão macroeconômica no segundo mandato Lula. Esta tese não tem apoio na história econômica recente do Brasil.

De qualquer modo, o autor, ao afirmar que "a estagnação era uma variável implícita no modelo de estabilização adotado no Plano Real", cria uma questionável descontinuidade entreas reformas estruturais do período $\mathrm{FHC}$ e o desempenho observado no governo Lula, queregistrou expressivo crescimento no emprego eredução da pobreza, especialmenteno quadriênio 2004-2007.

É claro que as condições econômicas internacionais também foram favoráveis e que o arranjo do Plano Real não funciona em qualquer contexto por força da instabilidade inerente ao ser sistema econômico global ${ }^{3}$. 0 ponto fundamental de debate é que não houve mudanças substanciais de condução macroeconômica que diferenciam a gestão Lula da gestão FHC nas décadas de 1990 e 2000. Pelo contrário, a literatura tende a convergir para a tese que as mudanças foram residuais ou nulas.

FomeZero eBolsa Família: o texto de eni Vaitsman traz uma perspectiva interessante ao associar os programas de transferência de renda à agenda da universalização. Diz ela: o queéconsiderado como avanço na área da educação e saúde nos anos noventa, a ampliação da descentralização federativa na saú- dee educação, a meu ver, é similar ao processo que se deu no âmbito da assistência social nos anos 2000, sobretudo após 2004. A expansão nacional do Programa Bolsa Família e sua convergência com o Sistema Único de Assistência Social ampliaram a descentralização federativa para 0 âmbito da assistência social, o componente até então relegado da seguridade social.

Neste contexto, segundo Vaitsman, a agenda de desenvolvimento social a partir de 2004 não implicaria a ruptura com a tradição do movimento de combate à fome e segurança alimentar orientando a agenda social no primeiro ano de governo, mas antes em seu redirecionamento. 0 combateà fome e à insegurança alimentar passaria a ser tratado como parte de uma visão integrada de desenvolvimento social

A unificação dos programas detransferência de renda e das áreas de segurança alimentar, transferência de renda e assistência social sob a gestão federal do M inistério do Desenvolvimento Social, significou uma nova orientação para enfrentar o problema do conjunto expressivo edifuso de benefícios assistenciais e da redundância de programas e superposição de beneficiários

$\mathrm{N}$ ão quero negar, com a tese da prioridade ao Programa Bolsa Família na agenda de segundo ano do governo Lula, que não tenha ocorrido mudanças significativas no trato da política de assistência social desde então. 0 limite do editorial para o meu texto não me permitiu ampliar o trato de políticas específicas, como pensara inicialmente. 0 exemplo assinalado pela autora, da adaptação do modelo da descentral ização cooperativa e pactuada do SU S à política de assistência social brasileira, é extremamente promissor e avançado. Este mimetismo é interessante, na experiência brasileira, porque a assistência social poderá usufruir de muitas virtudes da descentralização do SU S e corrigir os abundantes erros observados na experiência de delegação no setor saúde. Acho, de qualquer modo, pouco sustentável a defesa implícita feita por Vaitsman de que o Programa Bolsa Família tenha sido uma intervenção trivial na agenda política do governo Lula. Isto vai contra as evidências col hidas pelos estudos domésticos einternacionais. $\mathrm{O}$ trabal ho de Hunter e Powers éum bom exemplo deste tipo de reflexão; eles situam o Programa Bolsa Família como a principal marca do governo Lula4.

As perdas e os ganhos - Jeni está em desacordo com os meus números sobre perdas e danos na implementação do PBF. Diz ela: discordo quea unificação dos programas de transferência de renda no Programa Bolsa Família teria produzido uma redução de 4.722 .031 beneficiários de programas detrans- 
ferência de renda entre 2003 e 2006. 0 número do total de famílias beneficiárias no ano de 2003 (16.335.596 famílias) está distorcido, pois expressa duplicidade de famílias. Quando o Programa Bolsa Família foi criado em outubro de 2003, vários cadastros coexistiam e se superpunham e uma mesma família podia constar de diferentes cadastros. A unificação dos programas significou também a unificação cadastral, no Cadastro Ú nico dos Programas Sociais, quefoi aos poucos- ecom inúmeras dificuldadesoperacionais - filtrando as inconsistências e repetiç̃es e incorporando em uma mesma base de dados os beneficiários dos programas anteriores ao Programa Bolsa Família.

Os dados que utilizei no artigo são dados essencialmente secundários e divulgados pelas autoridades do Executivo federal. As objeções de Vaitsman devem ser consideradas com muita seriedade e credibilidade. Um caminho adicional, para esclarecer a divergência, pode ser uma revisão por pesquisas independentes das informações que levaram ao Cadastro Ú nico dos Programas Sociais do governo federal.

Vaitsman afirma adicionalmente que além da questão da quantidade, há um problema de qualidade, ou designificado. 0 Auxílio-Gás inchava o alcance dos programas sociais, pois embora a cobertura fosse de 8 milhões de famílias, os benefícios limitavam-se a 15,00 a cada dois meses. A unificação dos programas elevou 0 valor médio dos benefícios de transferência de renda, de 23,24 para 68,13 em valores de outubro de 2004. Esta observação da autora não nega os meus argumentos no artigo. Pelo contrário, serve para ratificar a minha tese das perdas quantitativas na cobertura quando da unificação gerada pelo PBF. Independente do que seja o julgamento sobre a pertinência ou abrangência de um ou outro programa social.

Virtude da gestão macroeconômica: os comentários de Carlos Pereira seguem uma linha singular e diametralmente oposta aos argumentos sobre os resultados perversos da gestão macroeconômica defendidos por Fagnani. A tese de Pereira é que a estabilização gerada pelo Plano Real gera benefícios aos pobres e, portanto, ela favorece o desenvolvimento social. Diz Pereira: “O controleinflacionário e o equilíbrio fiscal foram ganhos reais quea sociedade obteve com a agen da de ajuste, inclusive com repercussões sociais sobre a qualidade de vida e de renda dos mais pobres". Muitos estudos recentes sobre padrão de vida no Brasil ratificam a tese de Pereira.

Agenda de estudos comparativos - o comentário de Carlos Pereira abre uma interessante perspectiva para testar a hipótese sobre os efeitos da estabilização nos diferentes contextosnacionais. Diz Pereira que a austeridade no gasto público foi uma ameaça aos programas sociais nos países que optaram por uma agenda do ajuste macroeconômico. Ainda assim teria gerado, segundo Pereira, "ganhos reais de qualidade de vida dos mais pobres como consequência do equilíbrio macroeconômico." A experiência brasileira mostra que a estabilização tevequeaceitar uma complexa institucional idade do sistema de proteção social. Os avanços no padrão de vida dos pobres resultaram da estabilização combinada com o sistema de proteção social. 0 efeito redistributivo do PBF nos estratos mais pobres foi muito significativo.

Pereira ratifica a tese que eu defendo para o Brasil ao assinalar que"a agenda do ajustemacroeconômico não se contrapôs à agenda de proteção social, principalmente das políticas de saúde e educação".

Em resumo, a leitura de Pereira pode ser discutida sob uma outra perspectiva: a disponibilidade de recursos para os gastos sociais no Brasil pode ter sido também um resultado direto da estabilidade e do crescimento econômico dos anos recentes. A disponibilidade de recursos não pode ser vista como uma variável dissociada da gestão macroeconômica. É possível argumentar que o gasto social brasileiro teveum crescimento importanteepositivo no geral - mesmo considerando que nem todos setores sociais ganharam com este crescimento, como mostrei - como um resultado direto das decisões governamentais de estabilizar a gestão macroeconômica e manter o crescimento da carga fiscal. A notável aderência dos governos subnacionais à agenda social robusteceu, adicionalmente, as funções de proteção social no país. Resta agora responder por que os resultados sociais agregados se zerados os efeitos redistributivos do PBF - desta disponibilidade de recursos na área social têm sido tão medíocres comparados aos resultados observados em países com condições de gasto social semelhantes.

\section{Referências}

1. Steinmo S, Thelen K, Longstreth F. Structuring Politics - Historical Institutionalism in Comparative Analysis. New York: Cambridge University Press; 2005.

2. Cohen E, Franco R. Avaliação de projetos sociais. Rio de Janeiro: Vozes; 1993.

3. Belluzzo LG. Turbulências, Fundamentos e Risco Sistêmico. Jornal Valor 2006 Mai 30.

4. Hunter W, Power TJ. Rewarding Lula: Executive Power, Social Policy, and the Brazilian Elections of 2006. Latin American Politics and Society 2007; 49(1):1-300. 